\title{
Georges Bataille - Michel Leiris, Echanges et correspondances
}

\section{Emanuele Kanceff}

\section{Q OpenEdition \\ 1 Journals}

\section{Edizione digitale}

URL: http://journals.openedition.org/studifrancesi/36677

DOI: $10.4000 /$ studifrancesi.36677

ISSN: 2421-5856

\section{Editore}

Rosenberg \& Sellier

\section{Edizione cartacea}

Data di pubblicazione: 1 juillet 2005

Paginazione: 199-200

ISSN: 0039-2944

\section{Notizia bibliografica digitale}

Emanuele Kanceff, «Georges Bataille - Michel Leiris, Echanges et correspondances», Studi Francesi [Online], 145 (XLIX | I) | 2005, online dal 30 novembre 2015, consultato il 18 avril 2021. URL: http:// journals.openedition.org/studifrancesi/36677 ; DOI: https://doi.org/10.4000/studifrancesi.36677

Questo documento è stato generato automaticamente il 18 avril 2021.

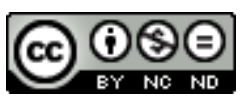

Studi Francesi è distribuita con Licenza Creative Commons Attribuzione - Non commerciale - Non opere derivate 4.0 Internazionale. 


\title{
Georges Bataille - Michel Leiris, Echanges et correspondances
}

\author{
Emanuele Kanceff
}

\section{NOTIZIA}

GEORGES BATAILLE - MICHEL LEIRIS, Echanges et correspondances, édition établie et annotée par Lows YVER. Postface de Bernard NOEL, Paris, Gallimard, 2004 («Les inédits de Doucet», collection dirigée par Yves Peyré), pp. 280.

1 Molto opportunamente questo cofanetto di oggetti personali è definito dai curatori «le déni de toute solitude et la communauté d'une dissidence». Si tratta, in effetti, di una raccolta di lettere scambiate tra i due amici, completato da scritti - che precedono la corrispondenza - in cui i due poeti si presentano e si commentano l'un l'altro. Veramente le due figure si sfiorano continuamente, quasi si toccano o si scontrano con delicatezza. La loro fraterna amicizia diventa con la scrittura che ne deriva un motivo e una modalità in più non solo di esprimersi ma di parlare al lettore. È Leiris ad iniziare il dialogo con quattro testi su Bataille molto fini, sul suo dongiovannesimo, sulla sua concezione dell'impossibile, sulla sua scrittura e la sua poetica; Bataillke risponde da suo pari con considerazioni sul surrealismo, sulla pubblicazione di Un Cadavre, il razzismo.

2 La corrispondenza qui raccolta occupa uno spazio di circa quarant'anni (1924-1961) e viene qualificata da Bernard Noel "une communication d'une qualité spécifique et remarquable". I testi delle lettere sono gradevoli quanto allusivi e non fanno mancare un po' di mistero; ma sono giudiziosamente annotati ed accompagnati da preziosi apparati e cornici adeguate di altri testi, come quelli di OEil, che seguono la corrispondenza. Una cronologia bio-bibliografica cerca di portare ulteriore chiarezza, così come la bibliografia dei periodici ai quali i due amici hanno entrambi collaborato. 